\title{
Successful en bloc endoscopic submucosal dissec- tion of a giant rectal laterally spreading adenoma
}


Fig. 1 Endoscopic submucosal dissection of a laterally spreading tumor in the rectum. a Colonoscopic view of the laterally spreading tumor. b Chromoendoscopic view with indigo carmine dye showing demarcation of the margin of the lesion. c Submucosal injection at $5 \mathrm{~mm}$ from the edge of the lesion. $\mathbf{d}$ Submucosal dissection and circumferential mucosal incision with a dual knife. e An artificial ulcer observed after removal of the tumor. $\mathbf{f}$ The resected specimen measures $14 \times 10 \mathrm{~cm}$.

A 71-year-old woman with diarrhea and weight loss was admitted to the hospital. Colonoscopy revealed a large laterally spreading tumor in the rectum, $5 \mathrm{~cm}$ from the anus. The mass was approximately $14 \mathrm{~cm}$ long and involved approximately five-sixths of the rectal circumference. Chromo-magnification endoscopy and endoscopic ultrasonography confirmed that the lesion did not involve the submucosa. After discussion with the patient, written informed consent was obtained before she underwent endoscopic submucosal dissection (ESD).

The procedure was done with the patient under deep sedation. A forward-viewing endoscope (GIFQ260; Olympus Medical Systems Corporation, Tokyo, Japan) was used with a transparent distal cap attachment (MH-588; Olympus). A solution of sodium hyaluronate and glycerol fructose premixed in a ratio of $1: 4$ was used for

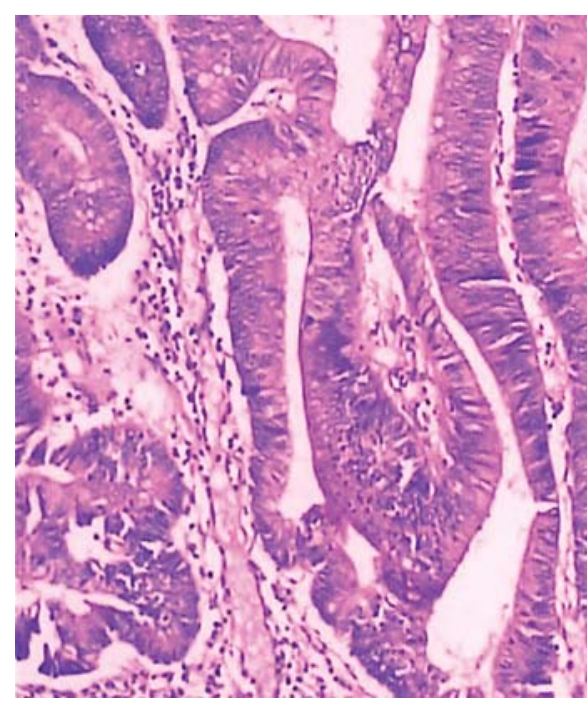

the submucosal injection. After the mucosa had been fully lifted, a circumferential incision was made around the lesion with a dual knife (KD-650Q; Olympus). En bloc
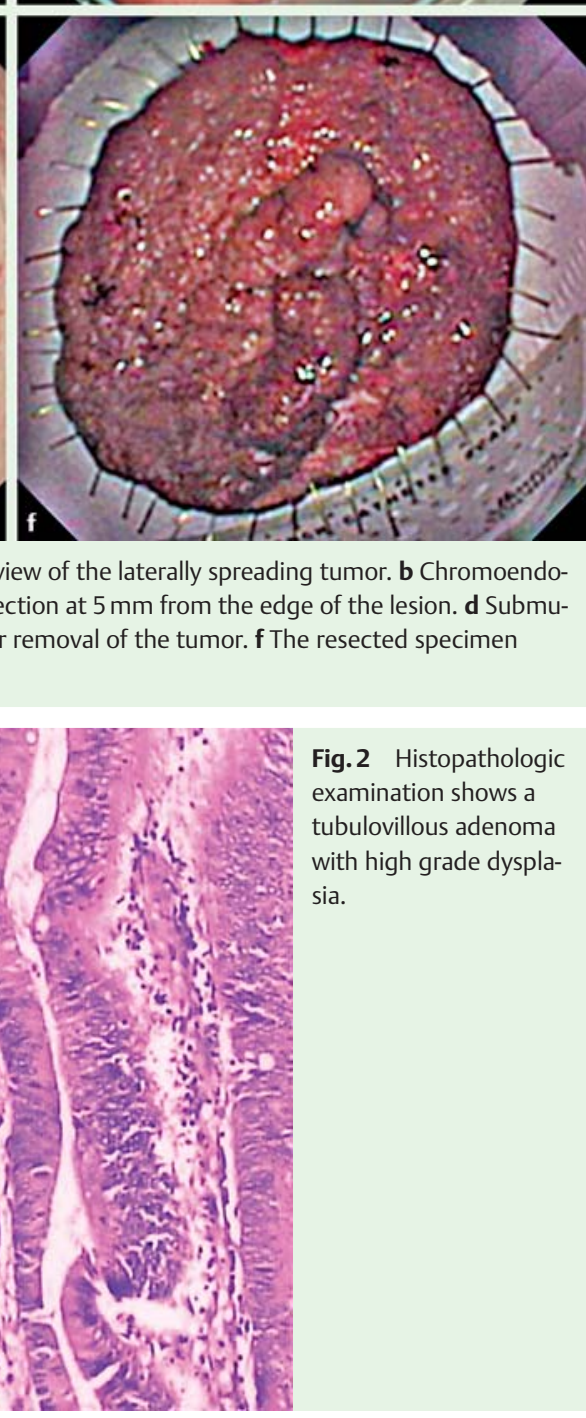

Fig. 2 Histopathologic examination shows a tubulovillous adenoma with high grade dysplasia.

removal was accomplished by progressively raising the lesion with repeated submucosal injections and dissection with the dual knife ( $\bullet$ Fig. $\mathbf{1}$ ). A coagulat- 
ing forceps (Coagrasper, FD-410LR; Olympus) was used to control any visible bleeding during the procedure. The total procedure time was 210 minutes. There was no major complication related to the procedure. The en bloc specimen measured $14 \times 10 \mathrm{~cm}$. Histopathologic examination showed a tubulovillous adenoma with high grade dysplasia ( $\bullet$ Fig. 2). At the 6-month follow-up, the wound was completely healed, with no residual neoplasm.

ESD has been demonstrated to be effective in the en bloc removal of colorectal laterally spreading tumors [1]. It has the advantages of allowing a complete pathologic evaluation of the specimen and a low rate of recurrence. Several authors have reported the successful en bloc resection of large colorectal laterally spreading tumors $(>9 \mathrm{~cm})$ by ESD [2-4]. In our case, we also demonstrated the feasibility and safety of using ESD to remove a large rectal laterally spreading tumor.
Endoscopy_UCTN_Code_TTT_1AQ_2AD

Competing interests: None

\section{Xiaowei Tang, Bo Jiang, Wei Gong}

Department of Gastroenterology, Nanfang Hospital, Southern Medical University,

Guangzhou, China

\section{References}

$1 \mathrm{Xu} M D$, Wang XY, Li QL et al. Colorectal lateral spreading tumor subtypes: clinicopathology and outcome of endoscopic submucosal dissection. Int J Colorectal Dis 2013; 28: 63 72

2 Fujishiro M, Yahagi N, Kakushima N et al. Successful endoscopic en bloc resection of a large laterally spreading tumor in the rectosigmoid junction by endoscopic submucosal dissection. Gastrointest Endosc 2006; 63: $178-183$

3 Antillon MR, Bartalos CR, Miller ML et al. En bloc endoscopic submucosal dissection of a 14- $\mathrm{cm}$ laterally spreading adenoma of the rectum with involvement to the anal canal: expanding the frontiers of endoscopic surgery (with video). Gastrointest Endosc 2008; 67: $332-337$

4 Yamazaki K, Saito Y, Fukuzawa M. Endoscopic submucosal dissection of a large laterally spreading tumor in the rectum is a minimally invasive treatment. Clin Gastroenterol Hepatol 2008; 6: e5-e6

\section{Bibliography}

DOI http://dx.doi.org/

10.1055/s-0034-1390756

Endoscopy 2014; 46: E615-E616

(c) Georg Thieme Verlag KG

Stuttgart · New York

ISSN 0013-726X

\section{Corresponding author}

Wei Gong, MD

Department of Gastroenterology

Nanfang Hospital

No. 1838, Guangzhou North Avenue 510515 Guangzhou

China

Fax: +8602061641541

drgwei@foxmail.com 